Published in final edited form as:

AdV Ther. 2017 August ; 34(8): 2007-2021. doi:10.1007/s12325-017-0587-7.

\title{
Patient Perspectives on Gene Transfer Therapy for Sickle Cell Disease
}

\author{
Strong Heather, M.A. ${ }^{1,2}$, Monica J. Mitchell, Ph.D. ${ }^{1,2}$, Goldstein-Leever Alana, Psy.D ${ }^{3,4}$, \\ Shook Lisa, M.A, MCHES ${ }^{5}$, Malik Punam, M.D. ${ }^{6,{ }^{*}}$, and Lori E. Crosby, Psy.D ${ }^{1,2,{ }^{*}}$ \\ ${ }^{1}$ Department of Psychology, University of Cincinnati; \\ 2Division of Behavioral Medicine and Clinical Psychology, Cincinnati Children's Hospital Medical \\ Center \\ ${ }^{3}$ Department of Pediatrics, Emory University School of Medicine; \\ ${ }^{4}$ Aflac Cancer and Blood Disorders Center, Children's Healthcare of Atlanta; \\ ${ }^{5}$ Division of Hematology, Cincinnati Children's Hospital Medical Center; \\ ${ }^{6}$ Division of Experimental Hematology \& Cancer Biology-Molecular Genetics, Cincinnati \\ Children's Hospital Medical Center
}

\section{Abstract}

Introduction: Sickle cell disease (SCD) is a chronic genetic disease with high morbidity and early mortality; affecting nearly 100,000 individuals in the United States. Bone marrow transplantation, the only curative treatment, is available to less than $20 \%$ of patients, due to a number of access barriers. Gene transfer therapy (GTT) has shown to be curative in animal models, and is approved for use in humans for early-phase studies at a few centers. GTT would offer a more accessible treatment option available to all patients. It is important to understand patient perspectives on GTT to help ensure human clinical trial success.

Methods: Two focus groups were conducted with younger (18-30 years) and older ( 231 years) adults with SCD to obtain data on patient knowledge and beliefs about GTT. Data from these two focus groups was used to develop a GTT educational brochure. A third focus group was conducted to obtain participant feedback on acceptability and feasibility of education and the brochure.

Results: Most adults, especially young adults, had little knowledge about GTT and expressed fear and uncertainty about the side effects of chemotherapy (e.g., hair loss, infertility), use of a human immunodeficiency virus (HIV)-derived viral vector, and potential for cancer risk.

Participants wanted full transparency in educational materials, but advised researchers not to share the vector's relation to HIV due to cultural stigma and no HIVvirus is used for the GTT-vector.

\footnotetext{
*Co-Senior Authors. Correspondence Details: Lori E. Crosby PsyD, Professor of Pediatrics, Division of Behavioral Medicine, Cincinnati Children's Hospital Medical Center, 3333 Burnet Avenue, MLC 7039, Cincinnati, OH 45229, lori.crosby@ cchmc.org, Phone: 513.636.5380, Fax: 513.636.7756.

Compliance with ethics guidelines: The Cincinnati Children's Hospital Medical Center and University of Cincinnati's Institutional Review Boards approved the study. All procedures followed were in accordance with the ethical standards of the responsible committee on human experimentation (institutional and national) and with the Helsinki Declaration of 1964, as revised in 2013. Informed consent was obtained from all patients included in the study.

Data availability: The datasets analyzed in the current study are available from the corresponding author upon reasonable request.
} 
Conclusions: Older adults had more desire to participate in human clinical GTT trials than younger participants. When recruiting for trials, researchers should develop GTT educational materials that address participant lack of trust in the healthcare system, cultural beliefs, fears related to side effects, and include visual illustrations. Use of such materials will provide adults with SCD the information they need to fully evaluate GTT.

\section{Keywords}

adults; risk perception; focus groups; gene transfer therapy; qualitative research; sickle cell anemia; treatment options

\section{Introduction}

Sickle cell disease (SCD) is a chronic genetic blood disorder with high morbidity and early mortality, affecting approximately 90,000 individuals in the United States [1] and millions worldwide. The disease results from the polymerization of sickle hemoglobin upon deoxygenation, resulting in change in the shape of the otherwise round red blood cells (RBCs) to sickle shapes. The hallmark of SCD is vascular occlusion of small blood vessels from sickled RBCs, and in turn, reduced blood flow, and oxygen delivery to tissues and organs.[2] In addition, the constant sickling and unsickling of RBCs makes them fragile and prone to hemolysis, resulting in anemia. These vascular occlusions, hemolysis and anemia largely contribute to symptoms and disease-related complications, such as pain episodes, infections, strokes, stunted growth, delayed puberty, infections, and chronic end organ damage, which can be severe and potentially life-threatening. [2,3] The chronic and episodic nature of this disease takes its toll and often causes psychological and emotional distress in patients, and severely affects quality of life.[4]

The treatment of SCD has primarily focused on managing symptoms and reducing complications. Daily hydroxyurea therapy is the most widely used treatment. It increases fetal hemoglobin and ameliorates symptoms of sickling, and was approved by the Food and Drug Administration for use in adults with SCD in 1998. In 2014, the National Heart, Lung and Blood Institute (NHLBI) recommended hydroxyurea be offered to all children with sickle cell anemia (HbSS and HbSB+Thalassesmia) age 9 months and older.[5] Although hydroxyurea has very few side-effects, it must be taken daily to work and patients must have their blood counts monitored regularly (i.e. every $1-3$ months). In addition, there is limited evidence of its benefits for adults with milder disease (less than 3 vaso-occlusive episodes per year) or other genotypes.[5] Bone marrow transplantation (BMT) from a matched sibling donor is the only curative treatment for SCD. BMT involves destroying the patient's own abnormal hematopoietic stem cells with high dose chemotherapy and transplanting donor bone marrow hematopoietic stem cells into an individual with SCD. The goal of BMT is to seed the bone marrow with new normal bone marrow that will begin to produce normal, non-sickling RBCs indefinitely.[6] BMT cures SCD in greater than 90\% of cases although there are serious risks associated with the procedure.[6] Moreover, less than $20 \%$ of the SCD patient population hasappropriately matched sibling donors available [6] and thus are eligible for BMT. Although BMT with non-sibling donors is being investigated, it has more 
immunological side effects, higher mortality rates and it will be several years before this treatment is readily available to patients. $[7,8]$

Gene transfer therapy (GTT) is treatment of a disorder or disease through transfer of engineered normal genetic material into human bone marrow cells to replace the defective gene or its function.[9] GTT often utilizes information from viruses to help transport genes into cells, without using any viral information. In SCD, GTT involves transferring an antisickling hemoglobin, treated in the lab, directly into the patient's bone marrow cells, initiating the production of normal RBCs that do not elongate and stick together in the body. [10] This GTT has been shown to cure SCD in animal trials. [11], GTT would offer SCD patients a 'one-time' curative treatment option that does not require a donor, as each patient is her/her own donor. It is also devoid of immune complications, as the patient's own bone marrow cells are utilized. Newer approaches like gene editing and correction are in preclinical stages, but GTT has been FDA approved for testing in clinical trials. [12] GTT has some of the same side-effects/risks as BMT. Patients will experience temporary hair loss and there is a risk that some patients will die from complications after the procedure. It is also possible that GTT has unknown side effects (e.g. cancer later in life).

With the onset of GTT human clinical trials, it is important to examine patients' perceptions of the use of GTT as a treatment for SCD. In this study, we used qualitative methods (focus groups) to explore adult patients' knowledge, beliefs, and acceptance of GTT as a potential treatment for SCD. We also sought to understand preferences for learning about GTT and used this data to develop and obtain feedback on an educational brochure for patients. Qualitative methods are particularly useful in exploring patient perceptions of multifaceted treatments, including GTT, as they enhance our understanding of participant's personal values and interpretation of educational messages, which may inform behavior and decisionmaking.

\section{Methods}

\section{Participants}

In 2009, adult patients ( $\mathrm{N}=103)$ from an SCD treatment center in the Midwest completed a preliminary survey assessing their awareness of GTT and interest in participating in a discussion group about GTT in the future during scheduled clinic or research visits (unrelated research studies). Patients with SCD who agreed to be contacted $(n=78)$ and were between 18 and 60 years-old were considered eligible for the current study.

\section{Procedures}

Prior to recruitment, this study received approval from the Institutional Review Board (IRB) at the institution where focus groups were conducted. All procedures performed, and compensation of participants was in accordance with the ethical standards of the responsible committee on human experimentation (institutional and national) and with the Helsinki Declaration of 1964, as revised in 2013. All eligible patients were contacted first by mail and then by phone. Informed consent was obtained from all participants prior to each focus group. 
Three focus groups were conducted between 2010 and 2012. The first two focus groups were intended to examine patient knowledge, beliefs, and acceptance of GTT. The study protocol was to conduct these focus groups with participants stratified by age, with one group of younger (18-30 years) and the other of older ( $\geq 31$ years). The third focus group aimed to obtain feedback on educational presentations and materials. This group included only younger (18-30 years) participants as early human trials are open to this age group. Fifty percent of the participants in the third group also participated in one of the previous focus groups as the goal was to obtain feedback to see if participants felt the brochure addressed issues identified in the first and second focus groups. The research team developed the content of the brochure based on data from the focus groups. A mixture of text and images were used to facilitate ease of understanding. The Flesch-Kincaid reading level for the brochure was eighth-grade. The goal was to develop content that could be adapted to other forms of written, electronic or verbal media (e.g. flyer, website, verbal communication).

Participants of the first two focus groups completed the GTT Survey during the focus group study visit. Focus groups were conducted by two trained moderators ( $\mathrm{LC}, \mathrm{JH})$ in the format recommended by Krueger and Casey. [13]Focus groups began with an opening question, followed by introductory questions, key questions, ending questions, a summary and final questions. [13] Following participant discussion, a hematologist and expert in GTT (PM), facilitated a Q\&A segment, using a presentation with illustrations to help ensure that all participants were well-informed on all topics discussed and to clarify participant misconceptions. During each focus group, one moderator was responsible for memoing emerging ideas and notes about the group. After each group, the research team met to review these notes and identify themes and evaluate for saturation. [14]Focus group participants were provided with lunch and compensated with $\$ 50$ for their time and participation. Participants were provided transportation to and from the focus group when needed.

\section{Measures}

Demographics.-All participants completed a demographics form that assessed participant age, gender, income level, and highest grade completed. Participants also described their perceived level of disease severity (mild, moderate, or severe). A medical record review was conducted to collect data on SCD genotype.

GTT Survey.-The GTT survey was completed by the first two focus groups. The research team developed the GTT survey to quantitatively and qualitatively assess participant awareness of treatments for SCD including hydroxyurea, BMT and GTT including benefits and side-effects of all treatments words associated with GTT, and whether participants would consider GTT as a treatment option.

Focus Group Guides.-The focus group guides were structured using the qualitative research methodology recommended by Krueger \& Casey. [15] The content was developed to align with study goals and refined through a series of meetings between the researchers and clinic staff (i.e. hematologists, nurse practitioners, nurse care managers). For the first two focus groups, discussion topics focused on disease knowledge (i.e. have you heard of 
the term "gene"; what do you know about the different types of hemoglobin), SCD treatment knowledge (i.e. what current treatments are you aware of for SCD; what have you heard about GTT), and beliefs about SCD treatments (i.e. what are your thoughts and feelings about the various treatments for SCD; what are your concerns, if any, regarding the possible risks of GTT). Based on data gathered in the first two focus groups, the research team developed a GTT educational brochure (see Figure 1). The focus group guide for the third group included questions about messages, images, and terms for educational materials and a review of a GTT educational brochure's acceptability and usefulness. This is included, level of text detail, readability, and clarity of content and illustrations (i.e. does this [graphic or text] clearly describe GTT; was the information easy to understand; what additional information would you want to know about GTT).

\section{Data Analysis}

Qualitative data was collected and analyzed using a systematic approach outlined in the literature and utilized by the authors in other studies. $[14,16]$ Each focus group was video and audio recorded and later transcribed verbatim. Three trained coders (LC, HS, and MM) independently reviewed each transcript first to obtain an understanding of discussion content. For each group, transcriptions were then manually organized into one of four categories; questions/prompts, major themes, minor themes, and other topics. Coders then met to review coded data and resolve any disagreements, in order to establish a consensus on reoccurring themes within groups. [14]The GTT survey and demographic data were summarized using descriptive statistics. In an exploratory analysis, Pearson's chi-square was used to assess the association between survey responses (level of concern about risks, willingness to try GTT, and awareness of treatments), demographics (gender and family income) and clinical characteristics (SCD genotype and disease severity).

\section{Results}

\section{Sample Demographics}

Forty-two adults with $\mathrm{SCD}(\mathrm{N}=42 ; 48 \%$ male) participated across three focus groups (see Table 1). Participants were between 18 and 58 years of age $(M=27 \pm 11.04)$; most participants identified themselves as African-American (one identified as "other") and reported a family income between $\$ 14,000$ and $\$ 17,599$ (median). Participants represented three SCD genotypes: $\mathrm{HbSS}(83 \%), \mathrm{HbS}^{+} \mathrm{Thal}(10 \%)$, or $\mathrm{HbSC}(7 \%)$. Forty-four percent $(44 \%)$ of participants reported moderate disease severity, and $33 \%$ described their disease as severe.

\section{GTT Survey}

Analysis of GTT survey data revealed that 38\% of group 1 (ages 18-30) and 56\% of group 2 (ages 31-60) reported being aware of GTT as a treatment for SCD. Older participants had more positive impressions of GTT relating the treatment to words such as, "health", "empowerment", and "future." Participants were asked to rate how concerned they were about the risk of possible side effects from GTT(Table 2). When participants were asked to rate their concern for infertility on a $0-10$ scale $(0=$ not very much; $10=$ very much $)$, the 
younger cohort voiced greater concern $(\mathrm{M}=6.36 \pm 4.58)$ than the older group $(\mathrm{M}=5.64$ $\pm 4.13)$. When asked if they might consider GTT as a treatment option, the older cohort responded with a mean of $9 \pm 1.92$ on the $0-10$ scale, compared to a mean of $4.14 \pm 3.21$ for the younger cohort. Pearson's chi square revealed that among demographics and clinical characteristics, only SCD genotype was significantly associated with level of concern about infertility $x^{2}(14)=29.22, p=.01$.

\section{Themes Related to GTT Knowledge, Beliefs and Acceptance}

We conducted only two focus groups $(n=26)$ to examine general perceptions of GTT; however, saturation of themes was achieved within the groups (Table 3). The following themes emerged.

Limited Knowledge about GTT.-All participants reported limited knowledge of GTT. Participants also had misperceptions about GTT which resulted in concerns about GTT. When asked, many participants had not heard of the term "gene transfer therapy," nor had they heard of GTT as a treatment for SCD.

Negative Effects of Chemotherapy.-Once informed of the GTT treatment process, participants in both groups expressed a negative perception of chemotherapy and its use as a part of the GTT procedure. Participants' impression of chemotherapy was shaped by their knowledge of its use in treating cancer. This made participants more apprehensive to consider GTT, as they were concerned the chemotherapy would be "taxing on your body." Participants wanted assurance that chemotherapy used in GTT would not warrant the same negative effects that cancer patients experience ("would you still have the same effects of chemotherapy [when used in GTT] as you would treating cancer?"), inquiring about chemotherapy duration ("how long are you taking the medicine?"), recovery time ("how long will you be in the hospital?"), amount of chemotherapy received ("so it's just one set [of chemotherapy treatment received]"), and side effects (e.g. hair loss).

Fear of HIV.-Participants were averse to the use of the human immunodeficiency virus (HIV) vector as a delivery system for the hemoglobin F gene, describing this portion of the treatment as "scary." Respondents were afraid they might develop HIV, "you were trying to get a treatment for sickle cell and now you got HIV." Younger and older participants expressed concern that researchers might later find that the viral vector causes HIV.

Trading SCD for Cancer.-Hearing about the potential risks and side effects of GTT including cancer, infertility, hair loss, and "any other side effects I don't know about" contributed to participants perceiving GTT less favorably. The risk of developing cancer made participants feel they would be trading SCD for another potentially more chronic disease. Respondents stated that while SCD negatively impacts their quality of life and increases their chances of early mortality, they would prefer to continue their current treatment regimen than potentially develop another life-threatening condition. Finally, participants felt the potential risk of cancer was not worth being cured of SCD. 
Infertility Risk Too High._After being informed of the risk of infertility, many participants agreed, "it's [GTT is] a no go." Discussion among younger participants indicated that having children was important to their families. After being advised of alternatives to address infertility (e.g. storing sperm/eggs, using a donor) participants' perceptions did not change. Moreover, participants expressed that fertility preservation techniques were "too much;" another added, "that just sounds like a longer process, trying to get your eggs back in you after you've gone through that."

Apprehension about GTT.-After learning about GTT, younger and older participants were less accepting of GTT ("so you say the FDA hasn't approved it yet?;" "there has to be a reason why your [hemoglobin] F gene turns off, why would you turn that back on.").There were differences in perceptions between younger and older participants' acceptability of GTT (see Table 3). Younger participants were more skeptical of GTT with some stating GTT "wouldn't even be on the options of treatments." Younger participants also shared that they would not select GTT largely due to side effects and concerns about vector safety. Younger participants noted that they would be more likely to consider GTT, and participate in clinical trials "if you [researchers] were actually in the clinical stages;" and could provide successful human trial data from a large sample.

Older participants viewed GTT as a progression in SCD treatment and described GTT as "amazing" and "gives you hope for the future." Discussion indicated that older participants held altruistic motivations for wanting to participate in clinical trials.

\section{GTT Educational Materials}

Participants in the third focus group discussed the design and content of educational materials and messages (Table 4). They also rated the brochure on helpfulness, ease of understanding, clarity of content and illustrations, willingness to share with others and utility for decision making about participation in GTT (see Table 5). Major themes from the focus group were as follows:

Information on GTT Trials.-Participants shared that educational materials should include clinical trial data. Participants noted that presenting longitudinal outcomes from a larger sample size would give them more confidence in the reported safety, efficacy, and side effects of GTT ("it might be safe now, but it's so much stuff they [the FDA] has approved and ....recalling back"). They also expressed interest in more explicit reporting of the side effects and risks of GTT based on these trials. Participants were concerned that there might be undiscovered side effects or risks that would impact their decision making. One participant inquired, "off the top of your head, as a doctor, what would you think would be the [other possible] side effects?"

Personalized Information about GTT.-Participants also sought information on how their SCD treatment history might impact GTT (e.g. "what if you're on something other than hydroxyurea before transplant, blood thinner, vitamins;" "would one treatment affect another one"). Participants wanted assurance that neither their past nor current treatment selection would negatively interact with GTT, reducing GTT's efficacy or increasing GTT-related 
risks. Participants also sought educational materials to detail if and how their treatment history would determine their eligibility for GTT or require a modified treatment process (e.g. the use of more chemotherapy).

No Information on HIV.- - Respondents advised that educational materials not include that the viral vector used in GTT is also used to carry the HIV virus. Participants felt that describing details about the HIV vector created more questions and uncertainty about GTT ("it makes the treatment sound more scary"). Participants stated, "just don't tell anybody you all are using HIV" when sharing materials with patients; other participants advised "don't even bring it up," due to the negative connotation of HIV. If information about the vector's origins is going to be shared, then materials should reiterate that the virus is not present "because it was never in the shell." Participants suggested, "don't say the HIV virus is taken out" of the shell since the vector is actually manufactured in the lab. Instead, they urged the research team to "just say you make the shell."

Feedback on GTT Educational Brochure (Figure 1): Clear and Helpful.-Overall, participants encouraged the research team, "don't sugar coat nothing" when developing educational materials. When asked to give their opinion on readability and clarity of information of the educational brochure, participants reported it was "clear" and "helpful" in increasing their knowledge about GTT; sharing "it taught me something new." Specifically, participants expressed that the use of illustrations, in addition to text, helped them to understand GTT; “especially for visual people, I like to see things." Participants also noted that including the percent of likelihood of risks was helpful in forming their opinions about GTT. Respondents also shared that they were not overwhelmed by the amount of information and detail (e.g. steps in procedure, comparison to other treatments, side effects) presented, highlighting that they "appreciated the honesty."

\section{Discussion}

This study used focus groups to gain an in-depth understanding of SCD patients' current knowledge, beliefs, and acceptance of GTT. We also examined patients' preferences for educational messages and materials including content and visuals. Study results indicated that the majority of participants were not familiar with GTT as a treatment for SCD and of the few participants with knowledge, it was limited. Thus, our findings support the importance of providing patients with detailed education on SCD treatment options including GTT. Study participants' expressed a significant level of fear regarding GTT due to misconceptions about GTT and possible risks and side effects. There was a perception that during GTT, one could receive a chronic condition (e.g. bi-polar disorder) from a donor. Once the discussion turned to possible risks and side-effects, the level of enthusiasm for GTT steadily decreased. In general, patients, stated that more research is needed to determine the potential for GTT and its benefits for SCD patients in the future.

Of particular concern was the risks associated with chemotherapy as well as getting cancer in the future, or as some participants expressed, "trading one chronic disease for another." The risk of infertility was a major concern across the groups. Not being able to have biological children was viewed as too high of a trade-off for a cure for SCD. The group 
consensus about this remained unchanged even after discussing fertility preservation options. These findings are consistent with previous research on risk perception of hydroxyurea treatment in parents of children with SCD. Meyappan and colleagues (2005) found that parents of children with SCD were unwilling to consider a treatment if there was a risk of cancer and the majority would not risk birth defects. [17] Disease severity also played a role with parents of children with higher disease severity being willing to accept more risk. Risk perception may also be impacted by past experiences with the healthcare system or a historical distrust of research as studies have demonstrated that negative experiences with the healthcare system are not uncommon for adults with SCD.[18, 19]

Age was a factor in some perceptions of GTT, as some older participants expressed that GTT is a potential cure for the future and a treatment that they wished they had known about when they were younger. In contrast, younger patients had major concerns about losing their hair, even temporarily, because of chemotherapy. Although the research team clarified that the vector does not contain any HIV genes, cannot give them HIV, and was made in the lab using information about the shell of HIV, younger participants continued to be skeptical. Although participants encouraged the research team not include information about the HIV vector, it would be unethical to do so. Participants would not have the information they need to make a fully informed decision that takes into account the pros and cons of GTT. We have since presented this information orally to a group of patients who were very receptive to the transparency. These families stated that they understood that the vector was created in the laboratory and would not carry the HIV virus.

Because participant knowledge can be a driving factor of successful enrollment and retention in clinical trials, providing detailed but easy to understand information about GTT to participants will be vital as the development of this treatment progresses. [20] A verbal overview of GTT could be supplemented with detailed printed or web-based information consisting of a combination of text, charts, and pictures to describe the process in a stepwise manner. Participants in the current study responded favorably to a brochure developed with this approach. This preference for visual depictions of information. including risk, is consistent with previous research on risk perception of SCD treatments. Patterson and colleagues recommend visual methods augment communication of numerical risk information. [21]

Researchers should consider ways to establish trust with participants to promote enrollment and retention in GTT trials. While there is limited literature on patient trust, research has suggested that SCD patients are more trusting of the health care team if they feel providers communicate information in an appropriate and clear manner. [19] Formulating an interdisciplinary research team that includes individuals from the SCD community may promote trust and, subsequently, enrollment in GTT clinical trials. [20] Individuals with SCD may be perceived by others as relatable and less intimidating in comparison to researchers. Sharing preliminary results of GTT studies with potential participants as they become available may help to facilitate trust with this population and improve enrollment in future studies. Engaging with participants over time may also provide opportunities to address questions and misperceptions, reduce stigma, and allow participants to weigh the benefits and risks of treatment options effectively. 
Conducting the study in a single treatment center limits the generalizability of the findings. While participants ranged in age, disease course, and health status, participants did not fully represent the broad spectrum of SCD patients. Future studies should use additional recruitment strategies to reach a broader sample of patients to more fully capture the diversity of this patient population and its perspectives. Furthermore, it would be important to determine the most effective way of educating children, adolescents, young adults and adults with SCD and their caregivers about treatment options including GTT, hydroxyurea and BMT. Older adults, for example, may have unique experiences and perspectives that they could share with younger patients. It would have been ideal to hold additional focus groups to engage patients in co-creating GTT educational materials (e.g. language, graphics, etc.) and to ask participants if the brochure/materials addressed initial concerns noted by focus group participants. The next iteration of the brochure will address specific issues (i.e. risks of infertility, cancer in the future). Any GTT educational materials should be evaluated for health literacy, another limitation of the current brochure. Finally, the GTT survey was developed for this study by the research team. Additional research is needed to determine the reliability and validity of this measure.

\section{Conclusions}

This qualitative study provides insights into the barriers and facilitators related to adults with SCD and their acceptance of and participation in GTT. Gene therapy, like BMT, is not a readily acceptable treatment modality for young adults with SCD due to fears of sideeffects/risks, and a lack of understanding of the treatment. After receiving education about GTT, many had questions, and while most did not want to be the first research participant, many were open to seeing data from GTT clinical trials before making a decision about whether they would participate in future clinical trials . Notably, older patients (31 years and older) expressed more desire to participate in gene therapy trials than younger patients (18 30 years); yet younger patients are more likely to be eligible for initial GTT trials. The success of GTT, including the recruitment and retention in clinical trials, will require education to dispel myths and explain the treatment, benefits and risks of GTT using a combination of visual, numerical and practical information (i.e. patient experiences). Only then can we examine the true potential of curative treatments like GTT for SCD.

\section{Acknowledgements}

The authors would like to acknowledge Janelle Hines (JH), Tamara Nordheim, Alexandra Bruck Durco, and Ellen Manegold for their support with data collection. The authors declare that they have no financial conflicts of interest. All named authors meet the International Committee of Medical Journal Editors (ICMJE) criteria for authorship for this manuscript, take responsibility for the integrity of the work as a whole, and have given final approval for the version to be published.

Funding. Dr. Crosby's time was supported in part by Grant \# K07HL108720, funded by the National Institutes of Health (NIH), National Heart, Lung, and Blood Institute (NHLBI). This work was also supported by the Doris Duke Clinical Scientist Award (to P.M.). The content is solely the responsibility of the authors and does not necessarily represent the official views of the NIH or the Doris Duke Foundation.

\section{References}

1. Hassell KL: Population estimates of sickle cell disease in the US. Am J Prev Med 2010, 38(4):S512-S521. [PubMed: 20331952] 
2. Rees DC, Williams TN, Gladwin MT: Sickle-cell disease. The Lancet 2010, 376(9757):2018-2031.

3. Zemel BS, Kawchak DA, Ohene-Frempong K, Schall JI, Stallings VA: Effects of delayed pubertal development, nutritional status, and disease severity on longitudinal patterns of growth failure in children with sickle cell disease. Pediatr Res 2007, 61:607-613. [PubMed: 17413865]

4. Panepinto JA, Bonner M: Health-related quality of life in sickle cell disease: Past, present, and future. Pediatr Blood Cancer 2012, 59(2):377-385. [PubMed: 22522407]

5. Yawn BP, Buchanan GR, Afenyi-Annan AN, Ballas SK, Hassell KL, James AH, Jordan L, Lanzkron SM, Lottenberg R, Savage WJ: Management of sickle cell disease: summary of the 2014 evidencebased report by expert panel members. JAMA 2014, 312(10):1033-1048. [PubMed: 25203083]

6. Gluckman E, Cappelli B, Bernaudin F, Labopin M, Volt F, Carreras J, Simões BP, Ferster A, Dupont S, de la Fuente J: Sickle cell disease: an international survey of results of HLA-identical sibling hematopoietic stem cell transplantation. Blood 2017, 129(11):1548-1556. [PubMed: 27965196]

7. Lê PQ, Gulbis B, Dedeken L, Dupont S, Vanderfaeillie A, Heijmans C, Huybrechts S, Devalck C, Efira A, Dresse MF: Survival among children and adults with sickle cell disease in Belgium: Benefit from hydroxyurea treatment. Pediatr Blood Cancer 2015, 62(11):1956-1961. [PubMed: 26173735]

8. Dallas MH, Triplett B, Shook DR, Hartford C, Srinivasan A, Laver J, Ware R, Leung W: Long-term outcome and evaluation of organ function in pediatric patients undergoing haploidentical and matched related hematopoietic cell transplantation for sickle cell disease. Biol Blood Marrow Transplant 2013, 19(5):820-830. [PubMed: 23416852]

9. What is gene therapy? [https://ghr.nlm.nih.gov/primer/therapy/genetherapy]

10. Hines J, Mitchell MJ, Crosby LE, Johnson A, Valenzuela JM, Kalinyak K, Joiner C: Engaging patients with sickle cell disease and their families in disease education, research, and community awareness. Journal of prevention \& intervention in the community 2011, 39(3):256-272. [PubMed: 26308311]

11. Levasseur DN, Ryan TM, Pawlik KM, Townes TM: Correction of a mouse model of sickle cell disease: lentiviral/antisickling $\beta$-globin gene transduction of unmobilized, purified hematopoietic stem cells. Blood 2003, 102(13):4312-4319. [PubMed: 12933581]

12. Ware RE, de Montalembert M, Tshilolo L, Abboud MR: Sickle cell disease. The Lancet 2017.

13. Krueger RA, Casey MA: Focus group interviewing Handbook of practical program evaluation 3rd edition San Francisco (CA): Jossey-Bass 2010.

14. Krueger RA: Analyzing focus group interviews. Journal of Wound Ostomy \& Continence Nursing 2006, 33(5):478-481.

15. Krueger R, Casey M: Focus Groups, a Practical Guide for Applied Research 4 edition SAGE publications. Inc, Thousand Oaks, California 2009.

16. Wu YP, Thompson D, Aroian KJ, McQuaid EL, Deatrick JA: Commentary: Writing and evaluating qualitative research reports. J Pediatr Psychol 2016, 41(5):493-505. [PubMed: 27118271]

17. Meyappan JD, Lampl M, Hsu LL: Parents' assessment of risk in sickle cell disease treatment with hydroxyurea. J Pediatr Hematol Oncol 2005, 27(12):644-650. [PubMed: 16344668]

18. Lattimer L, Haywood C, Jr, Lanzkron S, Ratanawongsa N, Bediako SM, Beach MC: Problematic hospital experiences among adult patients with sickle cell disease. J Health Care Poor Underserved 2010, 21(4):1114. [PubMed: 21099065]

19. Haywood C, Lanzkron S, Ratanawongsa N, Bediako SM, Lattimer-Nelson L, Beach MC: Hospital self-discharge among adults with sickle-cell disease (SCD): Associations with trust and interpersonal experiences with care. J Hosp Med 2010, 5(5):289-294. [PubMed: 20533577]

20. Peters-Lawrence MH, Bell MC, Hsu LL, Osunkwo I, Seaman P, Blackwood M, Guillaume E, Bellevue R, Krishnamurti L, Smith WR: Clinical trial implementation and recruitment: lessons learned from the early closure of a randomized clinical trial. Contemp Clin Trials 2012, 33(2): 291-297. [PubMed: 22155024]

21. Patterson CA, Barakat LP, Henderson PK, Nall F, Westin A, Dampier CD, Hsu LL: Comparing abstract numerical and visual depictions of risk in survey of parental assessment of risk in sickle cell hydroxyurea treatment. J Pediatr Hematol Oncol 2011, 33(1):4-9. [PubMed: 21178705] 


\section{A. \\ What is Sickle Cell Disease?}
20
Hemoglobin is a gene that is found in all of your Red Blood Cells. People with Sickle Cell Disease (SCD) have an abnormal He moglobin gene that they inherit from their parents.

Instead of a normal adult Hemoglobin A gene, people with SCD have a Hemoglobin $S$ gene. Hemoglobin $S$ makes the Red Blood Cells "sickle" and clump together.

Babies born with SCD have Hemoglobin $F$. Hemoglobin F prevents the blood from sickling, but it goes away as the baby gets older.

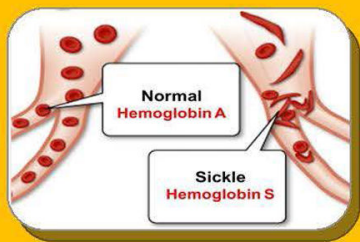

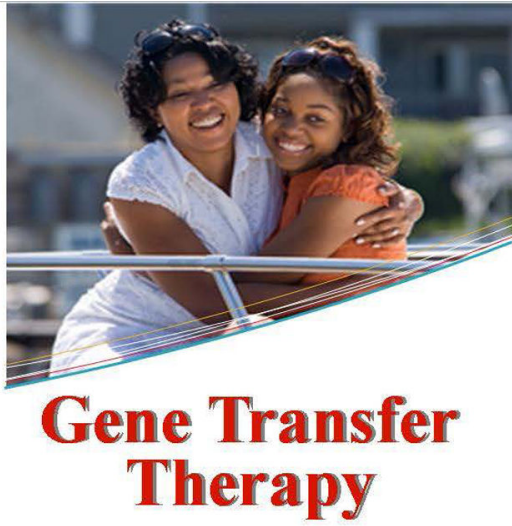

A New Treatment Under

Development for Sickle Cell Disease

\section{Cincinnati \\ Children's}

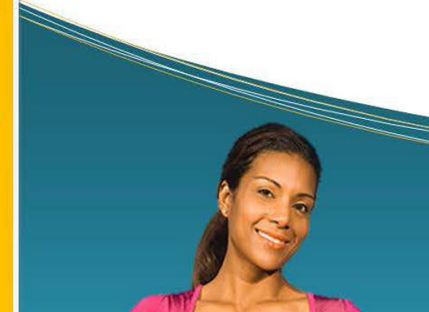




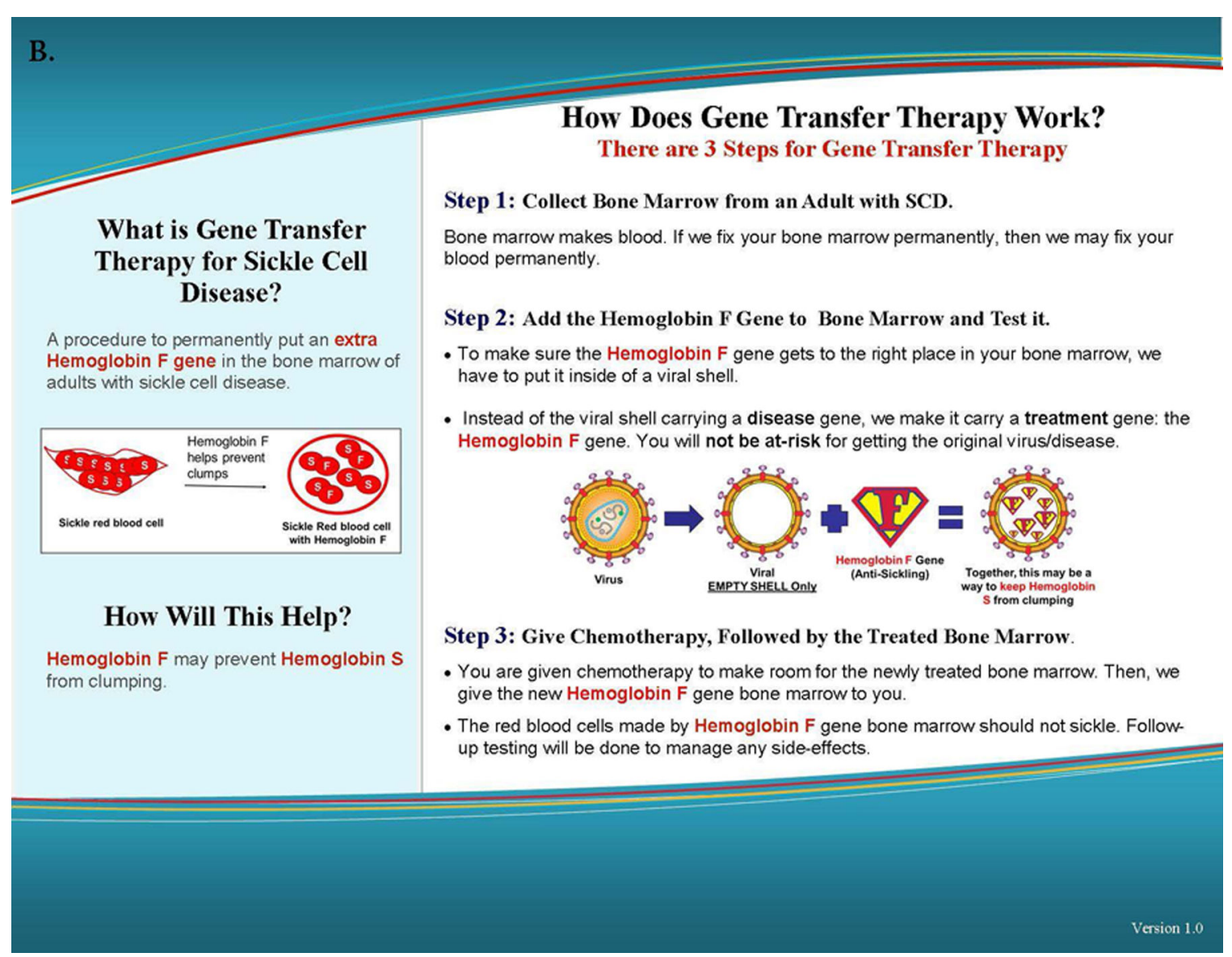

Figure 1.

Tri-fold educational gene therapy brochure. A. Side 1 of the brochure discusses sickle cell disease highlighting the role of fetal hemoglobin $(\mathrm{HbF})$. B. Side 2 of the brochure describes the gene transfer therapy process. 
Table 1.

Sample demographics

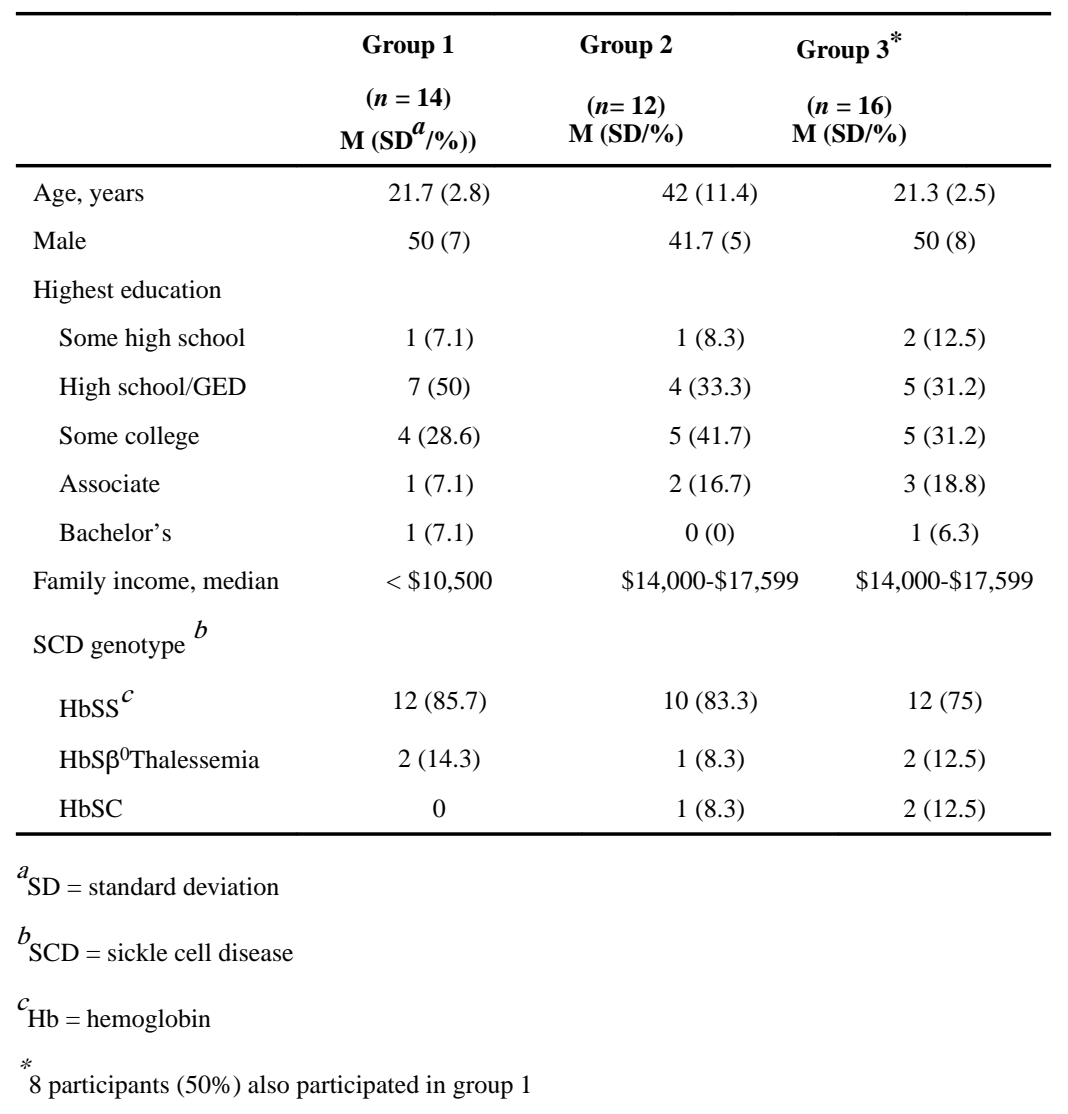


Table 2.

GTT Survey Responses

\begin{tabular}{|c|c|c|}
\hline & $\begin{array}{c}\text { Group } 1 \\
(n=14) \\
\mathrm{M}\left(\mathrm{SD}^{a} / \%\right)\end{array}$ & $\begin{array}{c}\text { Group } 2 \\
(n=12) \\
M(\mathrm{SD} / \%)\end{array}$ \\
\hline Willingness to try GTT $b$ & $4.14(3.2)$ & $9(1.92)$ \\
\hline \multicolumn{3}{|l|}{ Concern about GTT risks } \\
\hline Cancer later in life & $6.43(4.56)$ & $7.80(3.49)$ \\
\hline Infertility & $6.36(4.58)$ & $5.64(4.13)$ \\
\hline \multicolumn{3}{|l|}{ Treatments aware of } \\
\hline GTT & $3(37.5)$ & $5(55.6)$ \\
\hline $\mathrm{BMT}^{c}$ & $5(55.6)$ & $7(70.0)$ \\
\hline Hydroxyurea & $8(88.9)$ & $10(90.9)$ \\
\hline
\end{tabular}

${ }^{a} \mathrm{SD}=$ standard deviation

$b_{\text {GTT }}=$ gene transfer therapy

$c_{\text {BMT }}=$ bone marrow transplant 
Table 3.

Younger Adult and Older Adult Groups' Themes Related to Knowledge, Beliefs, and Acceptance of GTT

\begin{tabular}{|c|c|c|c|}
\hline Theme/Category & Younger Adult Group Themes \& Quotes & $\begin{array}{l}\text { Older Adult Group Themes \& } \\
\text { Quotes }\end{array}$ & Brochure Section \\
\hline Limited knowledge & $\begin{array}{l}\text { - Limited knowledge of GTT } \\
\text { - Younger participants were more misinformed ("I } \\
\text { heard if you do it you can take the risk of } \\
\text { getting what that person had, bi-polar, } \\
\text { schizophrenia, anything."). }\end{array}$ & $\begin{array}{l}\text { - Limited knowledge of GTT } \\
\text { ("doing } \\
\text { the blood test, and they take out } \\
\text { certain genes for it and put } \\
\text { different genes in."). }\end{array}$ & $\begin{array}{l}\text { - What is SCD? } \\
\text { - What is GTT for } \\
\text { SCD? } \\
\text { - How Will it Help? }\end{array}$ \\
\hline $\begin{array}{l}\text { Negative effects of } \\
\text { chemotherapy }\end{array}$ & $\begin{array}{l}\text { - Negative feelings about the potential for } \\
\text { discomfort related to GTT. } \\
\text { - Impression of chemotherapy was shaped } \\
\text { by their knowledge of its use in treating } \\
\text { cancer, which they associated with } \\
\text { negative outcomes ("would you still have } \\
\text { the same effects of chemotherapy [when } \\
\text { used in GTT] as you would treating } \\
\text { cancer?;" "I heard chemotherapy is } \\
\text { painful;" "isn't chemotherapy going to } \\
\text { make you sick and lose your hair?"). } \\
\text { - Younger participants expressed that } \\
\text { potential hair loss was a significant } \\
\text { deterrent ("your hair would fall out after } \\
\text { one time!"). } \\
\text { - Other younger participants expressed this } \\
\text { possible side effect would prevent them } \\
\text { from opting for GTT. }\end{array}$ & $\begin{array}{l}\text { - Negative feelings about the } \\
\text { potential for discomfort related to } \\
\text { GTT. } \\
\text { - Impression of chemotherapy was } \\
\text { shaped by their knowledge of its } \\
\text { use in treating cancer, which they } \\
\text { associated with negative } \\
\text { outcomes. }\end{array}$ & - Step 3 \\
\hline Fear of HIV & $\begin{array}{l}\text { - Averse to the use of the HIV vector as a } \\
\text { delivery system for the Hgb F gene and } \\
\text { were afraid they might develop HIV } \\
\text { ("you were trying to get a treatment for } \\
\text { sickle cell and now you got HIV;" "what } \\
\text { if they don't take it [HIV] all out."). } \\
\text { - Younger participants were upset that } \\
\text { researchers can dismantle HIV in a lab } \\
\text { but not cure terminal conditions ("they } \\
\text { know how to make HIV, this is crazy," } \\
\text { "but they can't cure cancer!;" "make a } \\
\text { cure for it [HIV] instead of making it } \\
\text { [HIV]."). }\end{array}$ & $\begin{array}{l}\text { - Averse to the use of the HIV } \\
\text { vector as a delivery system for the } \\
\text { Hgb F gene and were afraid they } \\
\text { might develop HIV }\end{array}$ & - Step 2 \\
\hline Trading SCD for cancer & $\begin{array}{l}\text { - The GTT risk of developing cancer } \\
\text { made participants feel they would be } \\
\text { trading SCD for another chronic disease } \\
\text { ("ya'll want us to get rid of sickle cell to } \\
\text { get cancer!;" "I've just been through so } \\
\text { much, so why would I put that on top of } \\
\text { it.") and the potential risk of cancer was } \\
\text { not worth being cured of SCD ("I would } \\
\text { rather just take my chances and just take } \\
\text { medicine every day;" "I'm cool with my } \\
\text { hydroxyurea, I'm already messed up"). }\end{array}$ & $\begin{array}{l}\text { - The GTT risk of developing } \\
\text { cancer made participants feel they } \\
\text { would be trading SCD for another } \\
\text { chronic disease and the potential } \\
\text { risk of cancer was not worth } \\
\text { being cured of SCD. }\end{array}$ & - Step 1 \\
\hline Infertility risk too high & $\begin{array}{l}\text { - The infertility risk made participants } \\
\text { hesitant to accept GTT ("it [GTT] really } \\
\text { sounds scary now, not being able to } \\
\text { have children."). } \\
\text { - Younger participants also expressed } \\
\text { apprehension because having children } \\
\text { was important to their families ("my } \\
\text { parents are all big on having } \\
\text { grandkids."). } \\
\text { - Fertility preservation techniques were } \\
\text { "too much." }\end{array}$ & $\begin{array}{l}\text { - The infertility risk made } \\
\text { participants hesitant to accept } \\
\text { GTT. } \\
\text { • Older participants' fear regarding } \\
\text { the risk of infertility was personal. } \\
\text { One participant who stated early } \\
\text { in discussion, "I'd like to be one } \\
\text { of the first people to try it } \\
\text { [GTT]," reconsidered this } \\
\text { statement adding, "it [GTT] really } \\
\text { sounds scary now, not being able } \\
\text { to have children." } \\
\text { - Fertility preservation techniques } \\
\text { were "too much." }\end{array}$ & Step 3 (side-effect) \\
\hline Apprehension about GTT & $\begin{array}{l}\text { - After learning about GTT younger and } \\
\text { older participants were less accepting }\end{array}$ & $\begin{array}{l}\text { - Older participants viewed GTT } \\
\text { as }\end{array}$ & Title \\
\hline
\end{tabular}




\begin{tabular}{|c|c|c|c|}
\hline Theme/Category & Younger Adult Group Themes \& Quotes & $\begin{array}{c}\text { Older Adult Group Themes \& } \\
\text { Quotes }\end{array}$ & Brochure Section \\
\hline & $\begin{array}{l}\text { of GTT ("so you say the FDA hasn't } \\
\text { approved it yet?;" "there has to be a } \\
\text { reason why your [hemoglobin] F gene } \\
\text { turns off, why would you turn that back } \\
\text { on."). } \\
\text { • Younger participants were more } \\
\text { skeptical due to risks/side effects, } \\
\text { concerns for safety, and lack of human } \\
\text { trial data ("the cancer, and HIV, and } \\
\text { hair loss, that's going to make me say } \\
\text { no;" "[maybe] if you [researchers] were } \\
\text { actually in the clinical stages"). }\end{array}$ & $\begin{array}{l}\text { a progression in SCD treatment } \\
\text { ("when we were younger they } \\
\text { didn't offer us any of this;"' } \\
\text { "[GTT is] amazing" and "gives } \\
\text { you hope for the future") and } \\
\text { were altruistically motivated to } \\
\text { participate in clinical trials ("it } \\
\text { might not be in my lifetime, but if } \\
\text { we can help someone else that's a } \\
\text { blessing," and many participants } \\
\text { agreed, "that's what it's all } \\
\text { about."). }\end{array}$ & \\
\hline
\end{tabular}


Table 4.

Themes on Participant Thoughts on Educational Materials

\begin{tabular}{|c|c|}
\hline Theme/Category & Summary and Quotes \\
\hline Information on GTT trials & $\begin{array}{l}\text { - Participants felt that presenting longitudinal outcomes in large human samples would give } \\
\text { them more confidence in the reported safety, efficacy, and side effects of GTT ("it might be } \\
\text { safe now, but it's so much stuff they [the FDA] has approved and ....recalling back"). } \\
\text { - Participants were concerned that there might be undiscovered side effects or risks that would } \\
\text { impact their decision making ("off the top of your head, as a doctor, what would you think } \\
\text { would be the [other possible] side effects?"). }\end{array}$ \\
\hline $\begin{array}{l}\text { Personalized information about } \\
\text { GTT }\end{array}$ & $\begin{array}{l}\text { - Participants wanted information on how their SCD treatment history might impact GTT and assurance } \\
\text { their history would not reduce GTT's efficacy or increase GTT-related risks ("what if you're on } \\
\text { something other than hydroxyurea before transplant, blood thinner, vitamins;" "would one treatment } \\
\text { affect another one."). }\end{array}$ \\
\hline No information on HIV & $\begin{array}{l}\text { - Participants felt that describing details about the HIV vector created more questions and uncertainty } \\
\text { about GTT ("it makes the treatment sound more scary"). } \\
\text { - Participants were concerned if information about the vector's origins is going to be shared, } \\
\text { then materials should reiterate that the viral vector is manufactured in a lab without the virus } \\
\text { ever being present ("because it was never in the shell;" "don't say the HIV virus is taken out } \\
\text { [of the shell]"). }\end{array}$ \\
\hline $\begin{array}{l}\text { Clear and helpful (Feedback on the } \\
\text { GTT educational brochure) }\end{array}$ & $\begin{array}{l}\text { - Participants recommended the use of illustrations in addition to text ("especially for visual people, I } \\
\text { like to see things.") helped them further understand GTT. } \\
\text { - Participants were not overwhelmed by details on the GTT process, risks/side effects, and } \\
\text { comparison with other treatments; they noted the importance of transparency ("[I] appreciated } \\
\text { the honesty;" "don't sugar coat nothing"). }\end{array}$ \\
\hline
\end{tabular}


Table 5.

GTT Educational Brochure Ratings

\begin{tabular}{|l|l|}
\hline$\underline{\text { Item }}$ & $\underline{\text { Mean Score }}$ \\
\hline The brochure helped me to understand SCD & 8.28 \\
\hline The brochure clearly explained the gene transfer therapy process & 8.22 \\
\hline The information was easy to understand & 8.83 \\
\hline $\begin{array}{l}\text { The brochure gave enough information about the gene transfer } \\
\text { therapy process }\end{array}$ & 6.72 \\
\hline $\begin{array}{l}\text { I would be able to share this brochure with a family member or } \\
\text { friend to help them understand the gene therapy transfer process }\end{array}$ & 7.56 \\
\hline $\begin{array}{l}\text { The brochure would tell me what I needed to know if I were } \\
\text { considering participating in a gene transfer therapy study }\end{array}$ & 7.65 \\
\hline
\end{tabular}

